\title{
Dicotomías, identificaciones y migraciones en las Américas
}

\author{
Leonir Mario Chiarello *
}

La construcción de la identidad americana ha estado determinada por rasgos dicotómicos que comienzan con la asimetría de poder presente en el encuentro entre los colonizadores ingleses y españoles y las poblaciones autóctonas. En este encuentro los colonizadores se impusieron sobre los autóctonos tanto a nivel político, económico y militar, como también cultural. Asfixiada desde entonces por el poder colonial español y, posteriormente, por el neocolonialismo estadounidense, América Latina ha intentado narrarse a sí misma desde distintos parámetros, pero generalmente ha caído en la perspectiva dicotómica heredada de europeos y norteamericanos que evidencia las diferencias entre el Norte desarrollado y rico y el Sur atrasado y pobre.

Este artículo pretende responder a la cuestión referente al rol de las migraciones en identificaciones dicotómicas entre América del Norte y del Sur. ¿En qué medida las migraciones influyeron estas identificaciones dicotómicas? Nuestra hipótesis sostiene que las migraciones internacionales fueron, y siguen siendo, factores, y al mismo tiempo consecuencia, de tales narrativas dicotómicas, más que las diferencias reales entre las dos partes del continente americano. El objetivo de nuestro estudio es investigar sobre la interacción existente entre la construcción de imaginarios, que se traducen en narrativas sobre la identidad cultural norteamericana o latinoamericana, y los flujos migratorios.

El artículo concentra su análisis en las inmigraciones europeas masivas que ingresaron en el continente americano desde fines del siglo XIX y en las actuales emigraciones masivas de latinoamericanos hacia Estados Unidos y Europa. Su

\footnotetext{
* Director Ejecutivo Scalabrini International Migration Network (SIMN).
} 
desarrollo seguirá tres momentos históricos específicos durante los cuales las migraciones internacionales y las identificaciones dicotómicas interactuaron en forma más evidente: a) fines del siglo XIX e inicios del XX, momento de las grandes olas migratorias europeas hacia el continente americano, b) siglo $X X$, cuando Estados Unidos asciende como potencia mundial y se convierte en el nuevo "Norte" de la migración Sur-Norte, y c) el actual contexto de globalización en el que los inmigrantes latinoamericanos residentes en Estados Unidos son percibidos como una amenaza para la seguridad nacional y la identidad cultural.

\section{La identificación dicotómica entre América del Norte y América del Sur y las inmigraciones masivas a fines del siglo XIX e inicios del XX}

El origen de la identificación dicotómica entre América del Sur y América del Norte se remonta a las rivalidades imperialistas entre la dinastía inglesa de los Tudor y la española de los Habsburgo, coronas que emprendieron la exploración y expansión colonial en el Continente Americano. Estas rivalidades, en un principio religiosas, permearon también las esferas política, económica, social y cultural, hasta el punto de convertirse en amplias narrativas que asemejaron el protestantismo inglés del Norte con riqueza, industria, progreso y liberalismo, y al catolicismo español del Sur con pobreza, agricultura, estancamiento y conservadurismo ${ }^{1}$.

Estas identificaciones antagónicas entre el Norte Anglo y el Sur Latino se acentuaron y consolidaron con los procesos de independencia de las colonias españolas, inglesas, portuguesa y francesas del Continente Americano entre 1776 y 1830, y la constitución de diferentes Estados-nación cuyos fines y metodologías se distinguieron diametralmente (ELLIOT, 2006). Las élites latinoamericanas adoptaron los ideales del liberalismo inglés, del racionalismo alemán y del iluminismo, además de los ideales de la revolución francesa, que defendía la voluntad soberana de la mayoría, y del positivismo francés, que proponía el rol central del Estado en la promoción de la modernización y el progreso de los países. Desde esta perspectiva, se constituyeron Estados fundados en un republicanismo autoritario, cuyo fin era garantizar la independencia de la dominación colonial y, al mismo tiempo, promover la modernización, el "orden y progreso" de los países integrados por poblaciones consideradas como "bárbaras". A diferencia de lo sucedido en América Latina, para las élites de Estados Unidos la independencia promovida por la revolución americana no fue un fin en sí mismo sino un medio para proteger los derechos individuales y limitar la capacidad de los Estados para avasallarlos (PETERSON, 1989). Desde esta perspectiva, además de desplazar a los países europeos, y especialmente a Inglaterra, España y Francia, de su influencia en la región apoyando los procesos de independencia de México del dominio español y, posteriormente, del dominio francés, Estados Unidos promovió los valores de la revolución americana, basada en la protección de 
las libertades y los derechos individuales, y la doctrina del panamericanismo, conocida también como doctrina Monroe, que reivindicaba "América para los Americanos" y promulgaba la unidad panamericana contra Europa (SEXTON, 2011). A pesar de su grandilocuencia, el proyecto de unidad del continente americano no se convirtió en realidad, porque el objetivo de Estados Unidos a través del panamericanismo era promover sus intereses geopolíticos en el continente contra el dominio colonial español y neo-colonial francés (MIGNOLO, 2005, p. 51-94).

Coincidió con este periodo del panamericanismo la promoción que Europa hizo de América como "tierra de promisión" para los millones de europeos que buscaban huir de la pobreza y el hambre producidas por la revolución industrial. En este contexto, los antagonismos entre América del Sur y del Norte se diluyeron, aunque sólo a nivel discursivo, y se fundieron bajo el mito de "hacer América", independientemente de que fuera América del Norte o del Sur. De esta forma, millones de europeos cruzaron el Atlántico para instalarse en el continente americano: Estados Unidos recibió el mayor número de inmigrantes, especialmente anglosajones (irlandeses e ingleses), y los países del Cono Sur a europeos del mundo latino, italianos en su gran mayoría. La década de $1880-$ 1890 fue caracterizada por el máximo absoluto de este flujo migratorio, cuando Estados Unidos recibió 15 millones de inmigrantes europeos, Canadá, dos, Argentina, tres, y Brasil 2,8 millones (SANTILLO, 1994).

La percepción de estos inmigrantes fue positiva tanto en los países emisores como en los receptores. En Europa la emigración fue considerada como "válvula de escape" de los problemas sociales provocados por la revolución industrial, y en el continente americano, especialmente América del Sur, la inmigración constituyó la posibilidad de importar ideas y costumbres modernas que permitirían modernizar y desarrollar sus propios países. Desde esta perspectiva, la mayoría de los países sudamericanos, entre los cuales destacan Argentina, Brasil, Uruguay, Venezuela, Chile y México (MÁRMORA, 1997), adoptaron políticas estatales específicas de promoción de la inmigración europea.

En este contexto, las élites, así como los intelectuales y académicos sudamericanos, además de apoyar la inmigración europea como forma de reemplazar el legado cultural colonial indo-ibérico, reprodujeron los imaginarios desarrollados por la racionalidad científica europea de la época, iluminista y positivista, sobre el estado salvaje, primitivo y de barbarie que debía ser erradicado de América Latina y pusieron sus esperanzas en soluciones europeas o norteamericanas. Hegel, Marx y Engels, por ejemplo, coincidían en señalar el carácter irracional e inferior de los latinoamericanos, lo cual justificaba la necesidad de la tutela europea o norteamericana sobre las nuevas repúblicas independientes (LARRAÍN, 1994, p. 41-44). Bajo esta perspectiva se desarrollaron las narraciones positivistas autóctonas en América Latina que coincidían con las provenientes de Europa: todas ellas concordaban en la superposición del patrón cultural europeo y las visiones despreciativas de la herencia salvaje y bárbara 
de la población local. Algunas expresiones de estas narrativas fueron las del argentino Domingo Faustino Sarmiento, que contraponía la raza blanca europea como civilización y los indo-mestizos como barbarie; el peruano Javier Prado, que presentaba la inferioridad de la raza latinoamericana como el principal obstáculo para el progreso; el boliviano Alcides Arguedas, que culpaba a los indios del subdesarrollo del país; o la del brasileño Euclides da Cunha, que consideraba a los mestizos como inferiores a los europeos civilizados, por citar algunos ejemplos (GISSI, 1982). Por otra parte, otras narrativas disidentes dentro de las élites criollas, como la del chileno Francisco Bilbao, el argentino Carlos Calvo o el colombiano José María Torres Gaicedo, se concentraron en la descripción del antagonismo entre el panamericanismo de América del Norte y la necesaria unión de los países de América del Sur, en sintonía con los ideales liberales franceses y en contraposición con la herencia colonial española y portuguesa. En este sentido, la inmigración europea y las narrativas eurocéntricas se convirtieron en instrumentos para proponer la modernización de América Latina (MIGNOLO, 2005, p. 67-72).

\section{El “Nuevo" Norte: el ascenso de Estados Unidos como potencia y la migración Sur-Norte}

El proceso masivo de inmigración europea hacia América Latina se interrumpió durante la depresión económica de la década de 1930 y el período entre las dos guerras mundiales. Estos años se caracterizaron por un retroceso en los procesos de liberalización e integración comercial, así como por un incremento en los niveles de proteccionismo de las economías, repercutiendo en la agudización del antagonismo Norte-Sur. Como reacción a este contexto y con el objetivo de proteger su mano de obra nacional, los países latinoamericanos cerraron las puertas a la inmigración e implementaron políticas restrictivas, provocando el agotamiento indeclinable de las inmigraciones europeas (CEPAL, 2006, p. 23-24).

En este contexto, surgieron las narrativas latinoamericanas críticas al racionalismo europeo. En un primer momento esta tendencia se manifestó en el movimiento indigenista, integrado por políticos, literatos, antropólogos, periodistas y artistas, que proponía el rescate de las raíces originales de la identidad indígena latinoamericana. Estas narrativas, que florecieron principalmente en México y Perú por el peso de las civilizaciones azteca e inca y la fuerte composición indígena de sus poblaciones, se basaban en una visión ingenua y romántica de las civilizaciones precolombinas como sociedades idílicas. En un segundo momento, numerosos ensayistas extranjeros y latinoamericanos buscaron identificar las peculiaridades de la identidad latinoamericana, destacando el carácter pesimista de tal identidad. Martínez Estrada, por ejemplo, sostenía que el resentimiento era la mejor expresión del carácter latinoamericano, mientras Octavio Paz mantenía que lo eran el vacío y el resentimiento profundo y Arguedas insistía que lo era 
la duplicidad. Si bien constituyeron propuestas alternativas sobre la identidad latinoamericana, el indigenismo y las versiones pesimistas acerca del carácter resentido y doble de los latinoamericanos nunca llegaron a ser dominantes ni ampliamente aceptadas. El límite de ambas perspectivas fue la visión esencialista con la cual pretendían definir el carácter latinoamericano, como si fuera inmutable en el tiempo, y su falta de confianza en la capacidad latinoamericana para asimilar el modelo europeo de cultura racionalista (LARRAÍN, 1994, p. 44-46).

Después de la Segunda Guerra Mundial, Estados Unidos ascendió como nueva potencia económica, política y militar mundial, y Europa, reconstruida y unificada, prosperó económicamente, convirtiéndose ambos en los polos de mayor atracción de mano de obra y en el nuevo "Norte" para millones de personas que emigraron en forma masiva desde los países del Sur del mundo, incluyendo América Latina. De receptora de inmigración europea, América Latina se convirtió en una de las regiones con los índices más altos del mundo de emigración hacia Estados Unidos y Europa. De conformidad con los datos del Censo de 2000, por ejemplo, cerca de 26,6 millones de personas nacidas en América Latina y el Caribe vivían fuera de sus respectivos países, lo que representaba el 4 por ciento de su población (MIRKIN, 2011, p. 24). En este contexto, la inmigración latinoamericana fue tolerada por Estados Unidos en la medida en que sirvió sus intereses. Ejemplos de ello son el programa braceros entre Estados Unidos y México, mediante el cual cerca de 200 mil migrantes mexicanos ingresaron anual y temporalmente en Estados Unidos entre 1942 y 1964, o el programa de acogida a los disidentes cubanos que escapaban del régimen socialista (DURAND; MASSEY and ZENTENO, 2001, p. 110-111). En este escenario, Estados Unidos se convirtió en el nuevo Norte de las migraciones, y las diferencias radicales entre Norteamérica y Suramérica fueron descritas, desde entonces, usando las categorías desarrollo-subdesarrollo, primer mundo y tercer mundo (BUFFINGTON and CAIMARI, 2009, p. 515-560).

En este nuevo contexto internacional controlado por Estados Unidos, en América Latina surgieron distintas narrativas, opuestas incluso al poderío norteamericano, pero aplicando ideas provenientes de Europa y de Estados Unidos. En la década de 1950, bajo la influencia de la sociología norteamericana y del éxito de la modernización e industrialización de Europa y Norteamérica, se adoptaron las teorías desarrollistas propuestas por la Comisión Económica para América Latina y el Caribe (CEPAL), que contemplaban la intervención directa del Estado para promover modernización e industrialización. Ante el fracaso de este modelo de modernización capitalista, a fines de los años 1960 y durante la década de 1970, aparecieron la teoría de la dependencia de América Latina respecto del imperialismo norteamericano, y los proyectos socialistas. A finales de los años 1970 y en la década de 1980, con el colapso de los sueños socialistas y la ola de dictaduras militares en América Latina se desarrollaron teorías conservadoras y neoliberales de libre mercado, que se consolidaron con el proceso de globalización (LARRAín, 1994, p. 47-48). 
En este contexto de fracasos continuos, los politólogos, sociólogos y otros estudiosos sociales críticos en América Latina iniciaron un proceso de desconstrucción radical de la racionalidad instrumental occidental y de revaluación de la identidad cultural supuestamente original de América Latina, en tres direcciones diferentes: a) el regreso a los principios culturales indígenas, que habían sido olvidados por la razón instrumental y los intentos modernizadores neoliberales, como sostenían, por ejemplo, Eduardo Galeano, Luis Guillermo Lumbreras y Aníbal Quijano; b) la síntesis cultural o mestizaje entre indios y españoles, cuya máxima expresión es la religiosidad popular, como afirmaba Pedro Morandé; y c) el posmodernismo, que proponía el abandono de los discursos totalizantes del racionalismo occidental modernista y el reconocimiento de la pluralidad cultural en América Latina, sostenido por David Harvey. El gran límite de estas narrativas fue, de nuevo, su perspectiva esencialista de la identidad cultural latinoamericana, considerada como una identidad inalterable, ya fuera indígena, mestiza o con diferentes elementos culturales (LARRAín, 1994, p. 49-57).

\section{La globalización y la migración Sur-Norte: "el Norte se vuelve Sur"}

La caída del muro de Berlín en 1989 consolidó el poder hegemónico de Estados Unidos a nivel mundial y el triunfo del capitalismo como único modelo socio-económico. Con este triunfo el capitalismo se expandió a nivel global y repercutió en la apertura de las fronteras para el intercambio de bienes, capitales, servicios, tecnología y, en teoría, mano de obra. Sin embargo, la integración global del mercado de trabajo siempre ha estado rezagada en comparación con la de bienes y capitales a causa de políticas migratorias restrictivas implementadas especialmente por los países receptores de migrantes, como la Unión Europea y los Estados Unidos. Pese a estas políticas restrictivas, las migraciones internacionales se han incrementado en forma sostenida a partir de la década de 1980.

En el caso particular de América Latina, la apertura del mercado de bienes y capitales no ha generado los efectos económicos esperados. Al contrario, la globalización ha tenido efectos adversos en la región, deteriorando gran parte de las economías nacionales, segmentando y precarizando el mercado laboral, aumentando la inequidad social y la pobreza, y elevando los niveles de violencia. Estos factores, sumados a las repercusiones de la crisis de la deuda externa, las guerras civiles, los conflictos armados y las dictaduras militares de las décadas de 1980 y 1990 y, en la última década, el incremento de la violencia, el crimen organizado y el tráfico de drogas, han generado flujos masivos de emigración desde el Sur del continente hacia Estados Unidos, los cuales representan un punto de inflexión en la inmigración latina hacia este país que algunos autores definen como la "latinización" o "hispanización" de los Estados Unidos (HUNTINGTON, 2004, p. 30-45). Entre 1990 y 2000, por ejemplo, de los 11 millones de inmigrantes que ingresaron en Estados Unidos, 4,6 millones eran 
latinoamericanos. De acuerdo con las cifras de los Censos estadounidenses de 2000 y 2010, la población de origen hispano o latino creció de 35,3 millones, que representaban el 12,5 por ciento de los 281,4 millones de habitantes en 2000 , a 50,5 millones, incluyendo los inmigrantes y sus descendientes, constituyendo así el 16 por ciento de los 308,7 millones de habitantes en 2010, y convirtiéndose en el primer grupo minoritario del país superando a los afroamericanos que representan el 12,6 por ciento de la población (UNITED STATES CENSUS BUREAU, 2011, p. 2).

Las cifras anteriores han dado pie a que las migraciones hayan vuelto a ser utilizadas, esta vez en Estados Unidos, por élites políticas y sociales y en las narrativas relacionadas con la identidad cultural para manifestar la preocupación de que el "Norte se está volviendo Sur" ${ }^{2}$. El incremento de la inmigración latinoamericana en Estados Unidos ha sido interpretado como un fenómeno de latinización asociado a la irregularidad migratoria, los bajos niveles educativos y el abuso por parte de los migrantes del sistema de seguridad social, constituyendo una amenaza económica, social y política para el país. El rápido incremento demográfico de la población latina en Estados Unidos ha prendido alarmas y estereotipos negativos, como los sostenidos por Samuel Huntington al afirmar que la llegada masiva de latinos, en su mayoría irregulares, constituye una amenaza tanto para la seguridad nacional, la soberanía territorial y fronteriza del país, como para la seguridad societal, entendida como la habilidad del pueblo estadounidense para preservar su cultura, instituciones y estilo de vida (HUNTINGTON, 2005, p. 221-256).

En sintonía con estas narrativas que instigan la tensión social y el rechazo hacia los hispanos, ciertos proyectos políticos como el Tea Party, con un fuerte contenido patriótico y anti-inmigración, contribuyen hoy a la defensa de una versión esencialista de la identidad norteamericana en cuanto anglosajona y protestante, versus la identificación amenazante y estigmatizada de los latinos, considerados como invasores incivilizados. En este sentido, la dicotomía Norteamérica-Suramérica asociada a las migraciones de fines del siglo XIX e inicios del siglo XX resurge, ahora, con una visión negativa de los migrantes, vistos no como constructores de modernidad sino como una amenaza para el proceso de modernidad norteamericana.

A pesar de la fuerza de esta dicotomía histórica entre Norteamérica y Suramérica, las estadísticas evidencian una realidad inmigratoria bastante distinta a la que las narrativas grafican. Más de la mitad de los inmigrantes latinos residentes en Estados Unidos, por ejemplo, cuenta con escolaridad secundaria completa o superior, en contraste con la afirmación de Huntington que los migrantes latinos no tienen educación (LOWELL, 2003). Por otro lado, recientes estudios del Departamento de Sociología de la Universidad de Princeton revelan que el gran flujo de inmigración irregular mexicana se ha detenido, constituyendo un histórico punto de inflexión en la larga y tensa historia migratoria MéxicoEstados Unidos de los últimos sesenta años ${ }^{3}$. Estos datos evidencian que el 
imaginario colectivo estadounidense está hoy alimentado por ideas que poco tienen que ver con la realidad, y que el inmigrante hispano se ha convertido en el chivo expiatorio que determinados sectores conservadores instrumentalizan para defender sus intereses en un período en que el país enfrenta una gran crisis financiera y la amenaza del terrorismo internacional.

Mientras en Estados Unidos se desarrollan estas narrativas estigmatizadoras de la inmigración latinoamericana como amenaza para la identidad nacional norteamericana y en Europa surgen narrativas sobre la identidad incierta que provoca la presencia de los inmigrantes, en América Latina, considerando que los flujos de migrantes salen de la región, se adoptan narrativas sobre la pérdida de capital humano, la necesidad de proteger los derechos humanos de los migrantes y de promover políticas migratorias a nivel interregional, pero sin una relación específica con la identidad de las migraciones internacionales (SPELLMAN, 2008, p.61-88).

\section{Conclusiones}

Las diferencias de nivel de desarrollo, industrialización y calidad de vida de sus habitantes entre el Norte y el Sur del continente americano son innegables. Sin embargo, la manipulación de los patrones de identificación y su asociación con superioridad e inferioridad de identidad cultural por parte de Europa y Estados Unidos a su conveniencia, les ha permitido utilizar las migraciones no sólo como un instrumento más para el desarrollo de sus economías, adoptando fronteras abiertas cuando les ha sido necesario y la fortificación de los muros cuando ya no son útiles, sino como medio para expandir su cultura, considerada civilizadora, o para defender la propia cultura ante la supuesta amenaza de la invasión latinoamericana.

La metáfora del melting pot, utilizada al inicio del siglo XX para describir a Estados Unidos como una nación hecha de inmigrantes, en la actualidad revela la vigente tendencia a asimilar los elementos culturales de los blancos y protestantes y rechazar a los demás elementos, entre los cuales se encuentran los latinoamericanos (JACOBY, 2004). Desde esta perspectiva, los inmigrantes latinoamericanos, al ser identificados como inferiores y pobres, deben mantenerse lejos, y por eso no sólo se construyen muros físicos, sino que también se fortalecen las fronteras artificiales y dicotómicas en los imaginarios sociales para poder proteger la propia seguridad nacional y societal.

América Latina ha experimentado asimismo cambios en su manera de auto-percibirse. Desde las perspectivas racistas de desprecio de las poblaciones autóctonas hasta las perspectivas indigenistas de resistencia al dominio europeo y norteamericano, pasando por las narrativas que buscan una síntesis cultural reconocida en el proceso de mestizaje de su población, todas ellas corren el riesgo de fijarse en el pasado marcado por la dicotomía entre el Norte desarrollado y el Sur subdesarrollado. La superación de esta dicotomía requiere una concepción 
de la identidad cultural entendida como un proceso histórico abierto al futuro, que está en permanente construcción y reconstrucción dentro de nuevas realidades y con nuevos elementos culturales, sociales, económicos, políticos y demográficos. Entre los elementos demográficos se encuentran las migraciones, las cuales se han convertido en un actor clave para el intercambio y el desarrollo de nuevos elementos identitarios.

\section{Notas}

1 - Para una visión sintética de los orígenes coloniales de la identificación dicotómica entre América del Norte y América del Sur, véase Mignolo (2005, p. 1-50).

2 - Para una síntesis de las narrativas sobre el Norte que se vuelve Sur, véase Fraga et al. (2010).

3 - Para conocer los detalles de estas conclusiones, véase Cave (2011).

\section{Referencias}

BUFFINGTON, Robert and CAIMARI, Lila. Keen's Latin American Civilization: History and Society, 1492 to the Present. Westview Press: Boulder, 2009.

CAVE, Damien. Better lives for Mexicans: Cut Allure of Going to North. In: New York Times, New York, vol. CLX, n 55.458, p.A8-A9, 2011.

CEPAL. Migración internacional, derechos humanos y desarrollo. CEPAL: Santiago de Chile, 2006.

DURAND, Jorge; MASSEY, Douglas and ZENTENO, René. Mexican Immigration to the United States: Continuities and changes. En: Latin American Research Review. Vol. 36, no. 1, p. 107-127, 2001.

ELLIOT, John. Empires of the Atlantic World: Britain and Spain in America 1492-1830. Yale University Press: New Haven, 2006.

FRAGA, Luís Ricardo et al. Latinos Lives in America: Making it Home. Temple University Press: Philadelphia, 2010.

GISSI, Jorge. Identidad, carácter social, y cultura latinoamericana. Hacia una psicología social dialéctica en América Latina. En: Estudios Sociales, n³1, p. 141-171, 1982.

HUNTINGTON, Samuel. The Hispanic Challenge. In: Foreign Policy, March-April, p. 30-45, 2004.

HUNTINGTON, Samuel. Who Are We? The Challenges to America's National Identity. Simon \& Schuster Paperbacks: New York, 2005.

JACOBY, Tamar (Editor). Reinventing the Melting Pot: the New Immigrants and What It Means To Be American. Basic Books: New York, 2004.

LARRAÍN, Jorge. La identidad latinoamericana. Teoría e Historia. En: Estudios Públicos, n 55 , p. 31-64, 1994.

LOWELL, Lindsay. Skilled Migration Abroad or Human Capital Flight? In: Migration Information Source, 2003. Disponible en: <http://www.migrationinformation.org/feature/display. cfm?ID=135>. Consultado el: 20 agosto 2012.

MÁRMORA, Lelio. Las políticas de Migraciones Internacionales. Alianza Editorial: Buenos Aires, 1997, p. 216-225.

MIGNOLO, Walter. The Idea of Latin America. Blackwell Publishing: Malden, 2005.

MIRKIN, Barry. La migración internacional en el Hemisferio Occidental: un estudio exploratorio. Scalabrini International Migration Network: New York, 2011.

PETERSON, Robert. A Tale of Two Revolutions: The Success of 1776 and the Failure of 1789. In: The Freeman: Ideas on Liberty, vol. 39, no 8, p. 313-319, 1989. 
SANTILLO, Mario. La migración masiva de los siglos XIX y XX hacia América Latina. En: AUZA, Néstor (Editor). El éxodo de los Pueblos, Manual de Teología y Pastoral de la Movilidad Humana. Consejo Episcopal Latinoamericano: Bogotá, 1994, p. 63-80.

SEXTON, Jay. The Monroe Doctrine: Empire and Nation in Nineteenth-Century America. Hill and Wang: New York, 2011.

SPELLMAN, William. Uncertain Identity: International Migration Since 1945. Reaktion Books: London, 2008, p.61-88.

UNITED STATES CENSUS BUREAU. The Hispanic Population 2010: Census Briefs. United States Census Bureau: Washington DC, 2011.

\title{
RESUMEN
}

Este artículo analiza el rol de las migraciones en identificaciones dicotómicas entre América del Norte y América Latina. Considerando las migraciones internacionales como factores y, al mismo tiempo, consecuencia de las narrativas histórico-culturales dicotómicas entre América del Norte y América Latina, el artículo concentra su análisis en tres momentos históricos específicos durante los cuales las migraciones internacionales y las identificaciones dicotómicas interactuaron en forma más evidente: a) fines del siglo XIX, cuando ingresaron significativos contingentes de migrantes europeos al continente americano, b) siglo XX, cuando Estados Unidos se convirtió en el nuevo "Norte" de la migración continental, y c) el periodo actual, en el que los inmigrantes latinoamericanos residentes en Estados Unidos son percibidos como una amenaza para la seguridad nacional y cultural.

Palabras clave: narrativas dicotómicas; identidad cultural; continente americano.

\begin{abstract}
This article analyzes the role of migration in dichotomous identifications between North America and Latin America. Considering international migrations as factors and, at the same time, consequences of historic and cultural dichotomous narratives between North America and Latin America, this article focus his analysis on three specific historical periods in which international migrations and dichotomous narratives interacted more evidently: a) the end of the XIX century, when significant contingent of European migrants arrived in the Western Hemisphere, b) the XX century, when United States became the new "North" of continental migration, and c) the current period, when Latin American immigrants in United States are perceived as a threat for national security and cultural security.
\end{abstract}

Keywords: dichotomous narratives; cultural identity; Western Hemisphere. 